\title{
A ZFM À LUZ DOS PRINCÍPIOS DA OMC: O PROCESSO PRODUTIVO BÁSICO VISTO COMO UMA POLÍTICA NECESSÁRIA AO DESENVOLVIMENTO REGIONAL
}

\author{
Juliana Oliveira Domingues ${ }^{1}$ \\ Gabriel Loretto Lochagin ${ }^{2}$
}

\section{Resumo:}

O objetivo deste estudo é refletir sobre a compatibilidade das políticas industriais da Zona Franca de Manaus (ZFM), especificamente os Processos Produtivos Básicos (PPBs), com o contexto de globalização comercial que, ao vedar diversas medidas discriminatórias, reduz também o espaço de elaboração e execução de políticas internas de desenvolvimento relacionadas ao apoio à indústria doméstica. Utilizando o método indutivo dentro de uma interpretação sistemática, propomos que o tema deve ser analisado diante da necessidade de estímulos regionais, com esforços maiores de ampliação do espaço de implantação de políticas de desenvolvimento no contexto multilateral.

Palavras-chave: comércio internacional; sistema multilateral de comércio; política industrial; ZFMPPB

\section{THE ZFM THROUGH WTO PRINCIPLES: THE BASIC PRODUCTIVE PROCESS SEEN AS A NECESSARY POLICY FOR REGIONAL DEVELOPMENT}

\begin{abstract}
:
The goal of this paper is to reflect upon the compatibility of industrial policies at the Free Economic Zone of Manaus, specifically the Basic Productive Processes, and the context of trade globalization which, by prohibiting many discriminatory measures, also reduces the possibilities of formulating and executing domestic development policies connected to supporting domestic industries. By means of a inductive methodology and a systematic approach, the theme shall be analyzed considering the necessity of regional incentives, aiming at expanding the possibilities of implementing development policies in the multilateral context.
\end{abstract}

Keywords: international trade; multileral trade system; industrial policy; ZFMPPB

\section{INTRODUÇÃO}

O sistema multilateral de comércio foi desenhado a partir do encontro de Bretton Woods de 1944 (Bretton Woods Agreement). Assim, após período intenso de guerras, o Acordo Geral sobre Tarifas e Comércio (GATT/47) procurou mecanismos de cooperação comercial entre as quarenta e quatro nações aliadas.

\footnotetext{
${ }^{1}$ Professora de Direito Econômico e Direito Financeiro da Faculdade de Direito de Ribeirão Preto/USP.

${ }^{2}$ Professor de Direito Econômico e Direito Financeiro da Faculdade de Direito de Ribeirão Preto/USP.
} 
Uma das linhas mestras traçadas em Bretton Woods foi a criação da Organização Internacional do Comércio (OIC) que teria como meta a coordenação e a supervisão da negociação de um regime, aplicado ao comércio internacional, com base no bilateralismo e multilateralismo. ${ }^{3}$ Por diversos fatores (i.e. supremacia dos EUA, fragilidade econômica da Europa, momento histórico etc.) a criação da OIC não foi exitosa ${ }^{4}$. Diante da impossibilidade da formação da OIC foi aprovado o acordo “possível” à época: o GATT/1947.

O Art. XXVIII do GATT/47 trouxe como previsão as denominadas "rodadas de negociação" para que as nações acordassem sobre os temas relacionados ao comércio internacional. Por meio de rodadas multilaterais periódicas de negociações, os Membros foram assumindo, cada vez mais, o compromisso de buscar eliminar as barreiras ao comércio internacional.

Dentre todas as rodadas, a Rodada Uruguai merece ser destacada por indicar a participação mais abrangente dos Países em Desenvolvimento (PEDs) e também por denotar uma negociação mais madura. ${ }^{5}$ Foi durante a Rodada Uruguai que houve o estabelecimento do single undertaking que substituiu ao sistema do GATT à la carte. Ou seja, a partir daquele momento, os Membros passaram, obrigatoriamente, a aceitar todos os pontos negociados como um único pacote de obrigações. ${ }^{6}$

Celso LAFER explica que o contexto motivou “"...] a aceitação da Rodada Uruguai, como linha política de inserção internacional do país". Para o Brasil era relevante a participação na criação do que ele denominou como "[...] um ampliado e rule-oriented sistema multilateral de comércio". ${ }^{7}$

$\mathrm{Na}$ Rodada Uruguai também se concluiu que o GATT/47 era insuficiente o que motivou a criação da Organização Mundial do Comércio (OMC) por meio do Acordo de

\footnotetext{
${ }^{3}$ THORSTENSEN, Vera. OMC - Organização Mundial do Comércio: as regras do comércio internacional e a nova rodada de negociações multilaterais. 2. ed. rev. e ampl. São Paulo: Aduaneiras, 2003, p. 29.

${ }^{4}$ VALËRIO, Marco Aurélio Gumieri. Organização Mundial do Comércio - Novo ator na esfera internacional. Revista de informação legislativa, v. 46, n. 184, p. 121-130, out./dez. 2009, p. 120.

5 "Os resultados da Rodada Uruguai determinam as regras do comércio internacional, não só dos grandes parceiros internacionais, para dirimir os conflitos entre eles, mas também dos pequenos e médios parceiros, que passam a ter na OMC a organização de supervisão e apoio para assegurar o acesso aos mercados protegidos dos próprios países mais desenvolvidos, bem como dos grandes acordos regionais de comércio". THORSTENSEN, Vera. OMC - As Regras do Comércio Internacional e a Rodada do Milênio. São Paulo: Aduaneiras, 1999, p. 39.

${ }^{6}$ THORSTENSEN, Id. Ibd. p. 41.

${ }^{7}$ LAFER, Celso. A OMC e a regulamentação do comércio internacional: uma visão brasileira. Porto Alegre: Livraria do Advogado, 1998, p. 42-43.
} 
Marraqueche. ${ }^{8}$ A OMC absorveu não apenas o GATT/1947 mas, também, todos os resultados e acordos negociados nas sete rodadas de negociações multilaterais.

A Rodada Doha tem sido considerada como a Rodada mais complexa e difícil, mas isso se deve a diversos fatores: temas mais sensíveis passaram a ser discutidos e, ao mesmo tempo, os Membros que antes não sabiam se posicionar de forma estratégica nas negociações (especialmente os PEDs) passaram a entender melhor as regras do jogo no comércio internacional.

A Rodada tem demonstrado que os temas e as discussões passaram a ser mais sofisticadas diante do amadurecimento dos Membros, assim como diante da variedade de posicionamentos, com oscilação entre as políticas liberais e protecionistas ${ }^{9}$. O número crescente de Membros da OMC e o fortalecimento do papel dos BRICs (Brasil, Rússia, Índia, China e África do Sul) no comércio e na economia mundial também cria um novo desenho para a $\mathrm{OMC}^{10}$.

E é dentro desse cenário que se insere o tema aqui proposto, uma vez que trataremos dos Processos Produtivos Básicos (PPBs) dentro da Zona Franca de Manaus (ZFM), em um contexto de comércio já globalizado, no qual o Brasil assumiu diversos compromissos e acordos dentro da OMC.

O objetivo deste estudo é refletir sobre a compatibilidade das políticas industriais da ZFM, especificamente os PPBs, dentro de um contexto de comércio global no qual não pode ser esquecido o ambiente desigual entre os players, em diferentes estágios de desenvolvimento econômico e social.

Nesse sentido, alguns Membros da OMC questionam as medidas de incentivo na ZFM, especificamente o PPB, diante do argumento de que não haveria mais margem para implementação de uma política industrial, considerando os termos dos acordos firmados pelo Brasil nas duas últimas décadas.

No entanto, o que buscaremos demonstrar, utilizando o método indutivo dentro de uma interpretação sistemática, é que o tema deve ser analisado diante da necessidade de estímulos regionais, considerando o meio ambiente e outras questões relacionadas à pesquisa e ao desenvolvimento.

\footnotetext{
${ }^{8}$ BARRAL, Welber. De Bretton Woods a Doha. In.: Welber (org). O Brasil e a OMC. 2. Ed. Curitiba: Juruá, 2002, p.15.

${ }^{9}$ DOMINGUES, Juliana O.; OLIVEIRA, Cristina B. G. de. Direito Econômico Internacional. Curitiba: Intersaberes, 2017, p. 91.

${ }^{10}$ Id. Ibid.
} 
Um dos pontos relevantes na agenda dos PEDs e do Grupo dos 20 (G-20) ${ }^{11}$ propriamente é trazer maior flexibilidade às regras das Medidas de Investimento relacionadas com o Comércio (Trade Related Investment Measures, Trims). Diante disso passa a ser aceitável o estabelecimento de níveis mínimos de conteúdo local que possam, em determinados períodos, viabilizar elevadas escalas para fornecedores locais, capacitando-os a competir no mercado mundial.

\section{Os princípios da OMC: uma análise voltada ao contexto das políticasadotadas} na ZFM.

Com base nas rodadas de negociação multilateral, alguns princípios passaram a ser indicados como essenciais ao livre comércio ${ }^{12}$. Dentre esses princípios, destacaremos o princípio da não discriminação (Artigo I do GATT), assim como o princípio da transparência e o famigerado princípio do tratamento especial e diferenciado para países em desenvolvimento.

Conforme reiteradamente explanado nos manuais de comércio internacional e nos próprios casos analisados pelo Órgão de Solução de Controvérsias (OSC) da OMC, o princípio da não discriminação é composto por outros dois princípios considerados complementares: I. Princípio da Nação mais Favorecida (NMF) e o II. Princípio do Tratamento Nacional $(\mathrm{PTN})^{13}$.

O princípio NMF é considerado como um dos principais pilares do sistema multilateral de comércio. Este princípio procura garantir que nenhum Membro obtenha uma vantagem comercial em suas relações com outro Membro que não possa ser estendida aos

\footnotetext{
${ }^{11}$ Formado por países desenvolvidos e em desenvolvimento, além da União Europeia, o G-20 tem por finalidade favorecer a coordenação entre seus membros, tendo se tornado, após 2008, um fórum central para a cooperação econômica internacional. Embora reunisse desde 1999 chefes do Banco Central e ministros da economia, após a crise financeira de 2008 passou a congregar chefes de Estado e de governo, promovendo negociações no nível político mais elevado (G-20. Historical Overview. Disponível em: <https://www.g20.org/Webs/G20/EN/G20/History/history_node.html>. Acesso em: 20 de maio de 2017.)

${ }^{12}$ Mais sobre esse tema, especialmente sobre todos os princípios norteadores do comércio internacional, veja-se: DOMINGUES, Juliana O.; OLIVEIRA, Cristina B. G. de. Direito Econômico Internacional. Capítulo 5. Curitiba: Intersaberes, 2017.

${ }^{13}$ Art. 01 do GATT: 1. Qualquer vantagem, favor, imunidade ou privilégio concedido por uma Parte Contratante em relação a um produto originário de ou destinado a qualquer outro país, será imediata e incondicionalmente estendido ao produtor similar, originário do território de cada uma das outras Partes Contratantes ou ao mesmo destinado. Este dispositivo se refere aos direitos aduaneiros e encargos de toda a natureza que gravem a importação ou a exportação, ou a elas se relacionem, aos que recaiam sobre as transferências internacionais de fundos para pagamento de importações e exportações, digam respeito ao método de arrecadação desses direitos e encargos ou ao conjunto de regulamentos ou formalidades estabelecidos em conexão com a importação e exportação bem como aos assuntos incluídos nos $\S \S 2$ e 4 do art. III.
} 
demais, evitando tensões e o desvio de comércio. Thorstensen explica que, de um lado, tratase de uma garantia ampla, ou seja, que pode envolver vários tipos de benefícios concedidos que distorcem os fluxos de comércio e a concorrência no comércio internacional propriamente. De outro lado, este princípio busca a estabilidade do sistema, uma vez que traz maior previsibilidade, promovendo, também, um ambiente equitativo aos exportadores quando estes optam pelo local onde há vantagens comparativas. ${ }^{14}$

A Cláusula NMF traduz a necessidade de um tratamento igualitário ao indicar que eventuais privilégios devem ser estendidos, com a propagação de políticas liberais. Veja-se que a própria abertura comercial gera, por si, um efeito multiplicador dos efeitos da Cláusula ${ }^{15}$.

Ainda que exista toda uma técnica de comércio que busca justificar e explicar o princípio da não discriminação, é importante observar que, na lógica comercial, existem muitos argumentos políticos. Seja qual for o caminho escolhido para justificar a existência da cláusula NMF, cabe destacar que a função do princípio, dentro da lógica do comércio, sempre foi o de mitigar as tensões entre os Membros da OMC.

De forma complementar, o PTN também coíbe a discriminação de tratamentos desiguais entre produtos nacionais e importados (artigo III do GATT). Sendo assim, o sistema multilateral compreende que as linhas mestras do comércio são aplicadas de forma não discriminatória, independente de causar ou não causar algum dano ao exportador: a mera discriminação traduz a violação ao princípio ${ }^{16}$.

Pode-se dizer, inclusive, que o PTN, como base do sistema multilateral de comércio, também foi estabelecido como uma forma de coibir práticas protecionistas que podem surgir de diversas formas sofisticadas e nem sempre fáceis de identificação, traduzidos em barreiras técnicas, por exemplo, ou barreiras sanitárias e fitossanitárias ${ }^{17}$.

\footnotetext{
${ }^{14}$ THORSTENSEN, Vera; RAMOS, Daniel; MULLER, Carolina. O Princípio da Nação Mais Favorecida e os desalinhamentos cambiais. Instituto de Pesquisa Econômica Aplicada. Brasília, 2011, p. 3.

${ }^{15}$ JACKSON, John H. The world trading system. Law and Policy of International Economic Relations. 2. Ed. Massachusetts Institute of Technology, 1997, p. 158-159.

${ }^{16}$ HOEKMAN, Bernard M.; KOSTECHI, Michel M. The political economy of the world trading system. 2. Ed. New York: Oxford University Press, 2002, p. 31.

${ }^{17}$ BARRAL, Welber Oliveira. O comércio internacional. Belo Horizonte: Del Rey, 2007. Veja-se também: CAPARROZ, Roberto; LENZA, Pedro (coord.). Comércio internacional esquematizado. São Paulo: Saraiva, 2012, p. 72.
} 
Por essa razão, sopesa-se com o princípio da transparência (i.e. outro princípio essencial). Thorstensen é uma das especialistas que claramente relaciona o PTN ao princípio da transparência em seus estudos. ${ }^{18}$

O princípio da transparência passa a ganhar muita importância em razão da necessária previsibilidade das regras aplicadas ao comércio internacional. Desse modo, este princípio ficou fixado no artigo X do GATT que estabelece que:

[a]s leis, regulamentos, decisões judiciárias e administrativas de aplicação geral, adotados por qualquer Parte Contratante e que visem à classificação ou avaliação dos produtos [...], serão prontamente publicados de maneira a permitir aos Governos ou aos comerciantes deles tomar conhecimento.

Lafer afirma que a transparência, além da evidente previsibilidade, traduz a intenção de contenção da "razão-de-estado" que é inerente ao "poder invisível". ${ }^{19}$ Sem dúvida, o significado da transparência é amplo a partir do momento que passa a ser visto também como uma obrigação dos Membros da OMC.

Quando as regras e procedimentos se tornam públicos, todas as políticas públicas tornam-se acessíveis para uma avaliação ampla sobre a razoabilidade e compatibilidade com as regras do comércio. Isto é especialmente relevante quando tratamos de políticas indústrias, tais como o próprio PPB na ZFM.

Nesse aspecto, aparentemente, o Brasil não deixou de dar publicidade às normas referentes aos PPBs, em que pese as questões terem surgido apenas após fatos específicos tornarem-se supostamente perniciosos ao comércio global. In casu, pode-se afirmar que a transparência das normas adotadas no Brasil foi essencial para que os demais Membros as questionassem na $\mathrm{OMC}$, pois a própria letra normativa da $\mathrm{OMC}$ estabelece que a publicação deve ser adequada, de forma a permitir o conhecimento dos governos e dos respectivos comerciantes.

Infere-se diante das questões que surgiram sobre os PPBs que uma discussão prévia das normas que alteram os procedimentos deveria ter a participação dos interessados, no contexto global (i.e. quando o produto em questão é comercializado internacionalmente e/ou sofre concorrência externa) para que não haja distorção na elaboração das normas. Isto porque uma avaliação prévia, no contexto global, poderia ajustar eventuais inconsistências, ou motivar os ajustes necessários que evitariam questionamentos posteriores. Entretanto, o

\footnotetext{
18 THORSTENSEN, 2003, p. 33.

19 LAFER, Celso. A OMC e a regulamentação do comércio internacional: uma visão brasileira. Porto Alegre: Livraria do Advogado, 1998, p. 27-28.
} 
processo legislativo e a formulação de políticas industriais não apenas no Brasil, mas nos demais países do globo, geralmente não estão abertos à comunidade internacional.

Ainda antes de adentrarmos no tema central, não podemos olvidar o princípio de concorrência leal, umas vez que o sistema multilateral de comércio tem como finalidade não apenas a abertura comercial, mas um comércio global justo e equitativo (vide, por exemplo, artigos VI e XVI do GATT). Talvez a avaliação deste princípio devesse ser ampliada dentro do contexto dos PEDs, numa interpretação diferenciada, com o escopo de permitir o "comércio justo e equitativo" em um ambiente que, inevitavelmente, é guiado pelo poder econômico de algumas nações. Esta questão geralmente é lançada nos debates e documentos de trabalhos da própria organização.

Os princípios norteadores do comércio são constantemente mencionados nas demandas e litígios diante da grande diferença entre os Membros, com distintas capacidades econômicas, diante de violações que podem causar danos diversos e afetar negativamente a concorrência internacional.

Nesse contexto, a neutralização dos efeitos negativos de práticas desleais passou a ser possível com os acordos que traduziram as medidas antidumping, e/ou subsídios, com a aplicação de medidas compensatórias. Entretanto, as práticas comerciais protecionistas foram se tornando mais sofisticadas de forma que a própria OMC precisou reavaliar seus instrumentos e identificar outras formas de barreiras ao comércio que passaram a ser aplicadas e que não são tão simples de identificar.

Dentro dessa análise principiológica que envolve o tema central do presente estudo, cabe mencionar de igual forma que o Brasil esta inserido no Princípio do Tratamento Especial e Diferenciado para Países em Desenvolvimento (Art. XXVIII e Parte IV do GATT/1994). Referido princípio visa o equilíbrio do sistema considerando a desigualdade entre os membros, coadunando-se com a intenção de construção de capacidades dos PEDs e seguindo as teorias do desenvolvimento. ${ }^{20}$

O fair trade deveria existir em um ambiente de igualdade, mas o evidente poder econômico de alguns Membros traduz a desigualdade nas relações comerciais e, também, no poder de barganha daqueles com melhores níveis de desenvolvimento.

Portanto, a avaliação do tratamento dos PEDs também depende de um "filtro" entre eles, considerando não apenas as suas necessidades, mas também a chamada capacity building e

\footnotetext{
${ }^{20}$ SALDANHA, Eduardo. Desenvolvimento e tratamento especial e diferenciado na OMC: uma abordagem sob a perspectiva da doutrina do stare decisis - Parte I. Revista de Direito Econômico e Socioambiental. v.3. n.1., 2012, p. 17.
} 
a sofisticação do arcabouço jurídico e político de cada Membro. É nesse ponto, em especial, que deteremos nossa reflexão sobre as políticas adotadas no Brasil, em especial o tema aqui proposto. 


\section{O PPB analisado à luz do seu histórico de criação}

O chamado Processo Produtivo Básico (PPB) passou a ser definido a partir da entrada em vigor da Lei n. ${ }^{\circ}$ 8.387, de 30 de dezembro de 1991. Em poucas linhas, o PPB passou a ser conhecido como "o conjunto mínimo de operações, no estabelecimento fabril, que caracteriza a efetiva industrialização de determinado produto" ${ }^{21}$.

O histórico do PPB remonta ao governo Collor, mas os primeiros Processos surgiram a partir do governo de Itamar Franco, ou seja, no início dos anos $90^{22}$. Este dado demonstra que o PPB passou a ser utilizado exatamente no momento histórico no qual houve a abertura da economia brasileira, período que antecede a criação da OMC (em que pese o Brasil já ser signatário do GATT/47).

Portanto, é um fato que, desde o início da década de 90, o PPB tem sido utilizado como uma contrapartida pelo Governo Federal à concessão de incentivos fiscais que são promovidos pela legislação da ZFM e, especialmente, pela Lei de Informática ${ }^{23}$.

O PPB estabelece as etapas fabris mínimas para as empresas que buscam os benefícios fiscais estabelecidos pela lei. Ou seja, para obter o benefício fiscal as empresas devem cumprir essas etapas para fabricar um produto determinado. As etapas são estabelecidas por meio de Portarias Interministeriais. Todos os PPBs são analisados e determinados pelos ministros da Indústria, Comércio Exterior e Serviços (MDIC) e da Ciência, Tecnologia, Inovações e Comunicações (MCTIC) ${ }^{24}$.

Há um Grupo Técnico Interministerial (GT-PPB) criado justamente para examinar, emitir pareceres e, quando necessário, propor a fixação, alteração ou suspensão de etapas dos $\mathrm{PPBs}^{25}$. Por meio do recebimento de uma proposta o GT/PPB, avaliará o pedido de fixação ou de alteração de PPB para um produto específico buscando a obtenção do máximo de valor

\footnotetext{
${ }^{21} \mathrm{Na}$ Zona Franca de Manaus, os produtos fabricados de acordo com o Processo Produtivo Básico recebem os seguintes incentivos: Redução de 88\% do Imposto de Importação (II) dos insumos importados; Isenção do Imposto sobre Produtos Industrializados (IPI) do bem final; Isenção da contribuição para o PIS/PASEP e da COFINS nas operações internas na Zona Franca de Manaus; Alíquota e credito diferenciados de PIS/PASEP e COFINS para venda em outras regiões do país.

${ }^{22}$ Vide BRASIL. MDIC. Competitividade Indústrial. O que é o Processo Produtivo Básico. Disponível em:< http://www.mdic.gov.br/index.php/competitividade-industrial/ppb/o-que-e-ppb> Acesso em: 15 maio 2017.

${ }^{23}$ Decreto n. ${ }^{\circ} 5.906 / 06$ (legislação de incentivo à indústria de bens de informática, telecomunicações e automação). Esses incentivos estão relacionados à redução do IPI para os bens de informática e automação produzidos em todo o País

${ }^{24}$ BRASIL. MDIC. Competitividade Indústrial. O que é o Processo Produtivo Básico. Disponível em:< http://www.mdic.gov.br/index.php/competitividade-industrial/ppb/o-que-e-ppb> Acesso em: 15 maio 2017

${ }^{25}$ A composição e o funcionamento do GT-PPB foram disciplinados pela Portaria Interministerial MDIC/MCT $\mathrm{n}^{\circ} 170$, de 4 de agosto de 2010. O Grupo é composto por representantes do MDIC, do MCTIC e da Superintendência da Zona Franca de Manaus (Suframa).
} 
agregado nacional, de acordo com a realidade da indústria brasileira em questão.

Portanto, pode-se concluir que a elaboração do PPB é negociada caso a caso, considerando a empresa interessada, seus fornecedores nacionais, assim como as empresas concorrentes no mesmo mercado e as associações representativas dos setores envolvidos ${ }^{26}$.

Do ponto de vista econômico, a presença de economias de escala ${ }^{27}$ em processos produtivos traduz um forte elemento que justifica uma política industrial com escopo de fortalecer a produção brasileira de forma competitiva, i.e., pensando também na abertura de mercado para a exportação dos produtos. O elevado potencial de ganhos de escala quando se otimiza a produção permite prever efeitos dinâmicos de diminuição de custos e de preços. Isto tende a resultar maior concorrência no mercado nacional e internacional.

Vale lembrar que o estabelecimento de um PPB envolve diversas diretrizes, entre as quais destacamos: i. investimentos para a fabricação do produto; ii. desenvolvimento tecnológico; iii. geração de empregos; iv. possibilidade de exportações do produto; v. investimentos em P\&D; vi. deslocamento de produção no Brasil em razão dos incentivos fiscais; entre outros.

Nesse contexto, cumpre primeiro observar que há uma série de fatores necessários para a composição e criação de um PPB. Ou seja, não se trata de uma politica criada sem critérios e sem requisitos prévios. Veja-se também que o índice mínimo de nacionalização sobre a importação na ZFM não cria condições para um exercício abusivo de poder de mercado $^{28}$ por parte dos produtores de insumos uma vez que, ao contrário, acabar por contribuir ao restabelecimento do equilíbrio no Brasil e ao desenvolvimento regional.

\section{PPB vs. OMC: compatibilidade ou incompatibilidade? Um visão do PPB como política pública à luz do desenvolvimento}

\footnotetext{
${ }^{26}$ BRASIL. MDIC. Competitividade Industrial. O que é o Processo Produtivo Básico. Disponível em:< http://www.mdic.gov.br/index.php/competitividade-industrial/ppb/o-que-e-ppb> Acesso em: 15 maio 2017.

${ }^{27}$ As economias de escala ocorrem nos casos em que o aumento de todos os fatores produtivos produz o aumento mais do que proporcional do nível de produção.

${ }^{28}$ Portaria $^{\circ} 50$ (Guia de Análise de Concentração da SEAE/SDE) destaca: "As importações e a possibilidade de importar são fatores que inibem o exercício de poder de mercado. Quanto maior for a participação das importações e/ou a possibilidade de importar, menor será a probabilidade de que o poder de mercado seja exercido. Note-se que um volume reduzido de importações não basta para se considerar provável o exercício de poder de mercado. Adicionalmente, deve-se considerar a possibilidade de que as importações aumentem, em quantidade e preços razoáveis, em resposta a um 'pequeno mas significativo e não transitório' aumento de preço. (...) Em princípio, será considerado o período de um ano e importações equivalentes a pelo menos $30 \%$ do valor de consumo aparente como razoáveis indícios de que a disciplina imposta pelas importações é suficiente para evitar o exercício de poder substancial de mercado.”, p. 12.
} 
A análise da compatibilidade entre os PPBs e as regras multilaterais de liberalização comercial deve partir de algumas considerações sobre as próprias finalidades das normas internacionais aqui referidas. A quais objetivos deve servir a Organização Mundial do Comércio?

Algumas indicações a este respeito encontram-se nos primeiros parágrafos do Acordo Constitutivo da OMC, em que se estabelece que as relações comerciais e econômicas devem levar em conta $^{29}$

[...] a elevação dos níveis de vida, o pleno emprego e um volume considerável e em constante elevação de receitas reais e demanda efetiva, o aumento da produção e do comércio de bens e de Serviços, permitindo ao mesmo tempo a utilização ótima dos recursos mundiais em conformidade com o objetivo de um desenvolvimento sustentável e buscando proteger e preservar o meio ambiente e incrementar os meios para fazê-lo, de maneira compatível com suas respectivas necessidades e interesses segundo os diferentes níveis de desenvolvimento econômico.

E o parágrafo seguinte postula, por sua vez, que ${ }^{30}$ :

[...] é necessário realizar esforços positivos para que os países em desenvolvimento, especialmente os de menor desenvolvimento relativo, obtenham uma parte do incremento do comércio internacional que corresponda às necessidades de seu desenvolvimento econômico.

Desta forma, não é necessário reiterar que abertura comercial e desenvolvimento não são temas mutuamente excludentes na atual disciplina multilateral das relações econômicas internacionais. A expansão e a abertura do comércio devem ser interpretados a partir destes valores, necessários à concretização dos objetivos de desenvolvimento expostos no Acordo Constitutivo da OMC.

Embora integração aos mercados globais e desenvolvimento não sejam diretrizes antagônicas, observam-se algumas críticas a agendas de integração que ignoram a construção de capacidades nacionais. Para que o comércio e os investimentos internacionais se traduzam em efetivo desenvolvimento para os países que ainda não o alcançaram, há a necessidade não

\footnotetext{
${ }^{29}$ No original, "raising standards of living, ensuring full employment and a large and steadily growing volume of real income and effective demand, and expanding the production of and trade in goods and services, while allowing for the optimal use of the world's resources in accordance with the objective of sustainable development, seeking both to protect and preserve the environment and to enhance the means for doing so in a manner consistent with their respective needs and concerns at different levels of economic development" (WTO. Agreement Establishing the World Trade Organization, 1994).

30 " $[T]$ here is need for positive efforts designed to ensure that developing countries, and especially the least developed among them, secure a share in the growth in international trade commensurate with the needs of their economic development" (WTO. Agreement Establishing the World Trade Organization, 1994).
} 
apenas de abertura, mas de sua combinação com a construção de instituições que favoreçam o crescimento e a redução das desigualdades ${ }^{31}$.

A respeito da relação entre as políticas de desenvolvimento e os acordos multilaterais de comércio, Rodrick pondera que a globalização e os processos de integração não devem ser interpretados como atalhos para o crescimento e o bem-estar, aspirando seu caráter substitutivo ao desenvolvimento das próprias forças e capacidades internas pelos Estados. São, sim, ferramentas complementares. É necessário que a integração seja acompanhada de inovações institucionais domésticas, as quais, adaptadas às características locais, não são fórmulas prontas. ${ }^{32}$

Trata-se de um constante desafio dos acordos multilaterais, portanto, prever as possibilidades de políticas de desenvolvimento no interior de documentos que promovem a abertura comercial. Este equilíbrio delicado encontra guarida em diversas previsões do GATT que procuraram reduzir a oposição entre os países industrializados e os menos desenvolvidos. Após a Rodada Tóquio (1979), por exemplo, conferiu-se aos países em vias de desenvolvimento tratamento preferencial, previsto em "cláusula de habilitação" (enabling clause), que passou a autorizar tratamento diferenciado e mais favorável a partir de um Sistema Geral de Preferências (SGP).

Isto não quer dizer que o espaço de políticas públicas nacionais seja irrestrito. Ao contrário, pode-se observar que os efeitos benéficos da integração são frequentemente combinados com outros menos positivos decorrentes da invasão do campo decisório das autoridades nacionais por políticas provenientes de foros externos ao Estado, restritivas da elaboração de políticas de desenvolvimento. Para contornar estes desafios é que as medidas de investimento relativas ao comércio devem ser dotadas de grau adequado de flexibilidade para assegurar que a maior abertura ao comércio e aos investimentos se combine com possibilidades efetivas de superação do subdesenvolvimento.

\footnotetext{
${ }^{31}$ Nesse sentido, veja-se também North . North, 1993: "Institutions are the humanly devised constraints that structure human interaction. They are made up of formal constratints (rules, laws, constitutions), informal constraints (norms of behavior, conventions, and self imposed codes of conduct), and their enforcement characteristics. Together they define the incentive structure of societies and specifically economies". Disponível em: < http://www.nobelprize.org/nobel_prizes/economic-sciences/laureates/1993/north-lecture.html> Acesso em: 15 maio 2017.

32 De acordo com o citado professor da Universidade de Harvard, "globalization is not a shortcut to development. Successful economic growth strategies have always required a judicious blend of imported practices with domestic institutional innovations. Policymakers need to forge a domestic growth strategy by relying on domestic investors and domestic institutions." (RODRICK, Nelson. Trading in Illusions. Foreign Policy, 18 de novembro de 2009. Disponível em: http://foreignpolicy.com/2009/11/18/trading-in-illusions/).
} 
Na agenda externa do Brasil está o tema da flexibilização das regras do TRIMs, de forma a ampliar o espaço de elaboração de políticas públicas nacionais, entre as quais podem ser situados os PPBs. Isto porque o TRIMs veda a aplicação, por parte de membros da OMC, de medidas incompatíveis com o disposto nos Artigos III e XI do GATT (referentes ao tratamento nacional e a restrições quantitativas). ${ }^{33}$

Assim, em 2002, o Brasil e a Índia apresentaram à OMC proposta apoiada ainda por outros países em desenvolvimento para que as normas referentes aos investimentos abrissem maior espaço para a heterogeneidade econômica e social dos países aos quais se aplicam, admitindo que diferentes estágios de desenvolvimento (manifestados em disparidades tecnológicas, sociais e relacionadas ao meio-ambiente) justifiquem a sujeição a regras também com características distintas. ${ }^{34}$ A proposta teve por finalidade amparar políticas de proteção à indústria doméstica com alto valor agregado, estimular transferências tecnológicas, aumentar a capacidade de exportação e promover pequenas e médias empresas.

É neste contexto que se situam diversas discussões relativas aos PPBS no Brasil. De um lado, trata-se de política industrial concebida para a geração de valor agregado em cadeias produtivas, com um nítido traço de política de desenvolvimento. De outro, o plano tem sido questionado internacionalmente como um privilégio para produtos domésticos em desfavor de produtos importados. Este foi o argumento com o qual a União Europeia iniciou processo de consultas na OMC a respeito do programa brasileiro. ${ }^{35}$

A adequação do PPB aos objetivos de desenvolvimento previstos como comandos constitucionais na ordem jurídica interna brasileira são, no entanto, argumentos que devem ser levados em conta na construção de suas políticas industriais. Este espaço previsto na Constituição para o desenho de políticas voltadas ao desenvolvimento é um elemento relevante para que o país possa se posicionar perante a exigência de maior flexibilidade em acordos multilaterais.

\footnotetext{
${ }^{33}$ Dispõe o Artigo III(4) do GATT: "[t]he products of the territory of any contracting party imported into the territory of any other contracting party shall be accorded treatment no less favourable than that accorded to like products of national origin in respect of all laws, regulations and requirements affecting their internal sale, offering for sale, purchase, transportation, distribution or use." Por sua vez, está previsto no Artigo XI(1) que "[n]o prohibitions or restrictions other than duties, taxes or other charges, whether made effective through quotas, import or export licences or other measures, shall be instituted or maintained by any contracting party on the importation of any product of the territory of any other contracting party or on the exportation or sale for export of any product destined for the territory of any other contracting party."

${ }^{34}$ CELLI Júnior, Umberto. Os acordos de serviços (GATS) e de investimento (TRIMS) na OMC: espaço para políticas de desenvolvimento. Cadernos PROLAM/USP, vol. 1, 2007, p. 3.

${ }^{35}$ CNI. Políticas Industriais Brasileiras em Cheque: Questionamento da União Europeia contra o Brasil na OMC. Observatório de Defesa Comercial, vol. 3, n. ${ }^{\circ}$, jan./abr. 2014, p. 1-8.
} 
Veja-se, a propósito, o conjunto de considerações feitas no Mandado de Segurança n. ${ }^{\circ}$ 11.862-DF, com relatoria da Ministra Eliana Calmon, julgado em 22/04/2009, em que o Superior Tribunal de Justiça teve oportunidade de se manifestar a respeito de atos da administração que instituem obrigações de aquisição de materiais nacionais para a produção de determinados bens, criando processos de valorização e expansão de cadeias produtivas nacionais. A edição da Portaria Interministerial n. ${ }^{\circ} 15$, de 25 de janeiro de 2006, dos Ministérios do Desenvolvimento, Indústria e Comércio e da Ciência e Tecnologia, estabeleceu o Processo Produtivo Básico do produto Pré-forma de Resina PET, industrializado na ZFM. A portaria estabelecia, entre outras, as obrigações de compra obrigatória, pelas empresas da Zona Franca, de 50\% do consumo de resina PET das empresas nacionais e a fixação prévia do preço máximo a ser praticado pelos fornecedores do insumo. ${ }^{36}$ Esta determinação administrativa ensejou, da parte de empresa obrigada a adquirir a matéria-prima no mercado interno, a impetração de mandado de segurança contra a decisão interministerial, alegando, basicamente, violação ao princípio constitucional da livre concorrência e falta de motivação para a prática protecionista.

Com base nos mandamentos constitucionais de garantia ao desenvolvimento nacional (artigo $3^{\circ}$, inciso II) e na competência dos órgãos ministeriais para elaborar e executar os planos nacionais e regionais de desenvolvimento econômico (artigo 21, inciso IX, combinado com o artigo 87, inciso II), decidiu-se legitimar a intervenção estatal no domínio econômico, aqui representada pelas regras de tratamento nacional no processo produtivo básico. Sua revogação poderia acarretar lesões à economia pública, o que afetaria não apenas o setor econômico específico de resina PET, "mas a própria economia brasileira e a concepção jurídico-institucional da Zona Franca de Manaus que a um só tempo propicia o desenvolvimento nacional e regional". ${ }^{37}$ Ainda,

[o] Processo Produtivo Básico (PPB) representa estratégia de alcance desse desiderato [o desenvolvimento nacional], por isso que a Portaria Ministerial que o instrumentaliza nada mais empreende do que exterioriza o poder normativo secundário dos Ministérios, consagrados no art. 87, II, da $\mathrm{CF} / 1988$, a qual admite o Estado como agente normativo e regulador das atividades econômicas voltado para o interesse público. ${ }^{38}$

\footnotetext{
${ }^{36}$ É que vem disposto no artigo $1^{\circ}$ da mencionada Portaria Interministerial.

${ }^{37}$ BRASIL. Superior Tribunal de Justiça. Mandado de Segurança n. ${ }^{\circ}$ 11.862-DF. Relatora: Ministra Eliana Calmon. Julgado em 22 de abril de 2009, p. 4.

${ }^{38}$ BRASIL. Superior Tribunal de Justiça. Mandado de Segurança n. ${ }^{\circ}$ 11.862-DF. Relatora: Ministra Eliana Calmon. Julgado em 22 de abril de 2009, p. 17.
} 
A decisão procura estabelecer a relação entre as políticas industriais de desenvolvimento e as normas internacionais, como expresso neste trecho:

[a] Tutela da Indústria Nacional é consectário do próprio desenvolvimento da nação, tanto mais que a Constituição regula a livre iniciativa dentro do nosso país, a concorrência dentro do nosso território, razão pela qual a própria Lei 8.884/94 determina a sua imperiosa aplicação mesmo que haja tratados internacionais em contrário, postura legítima diante da natureza hierárquica dos documentos transacionais em confronto com as leis federais; art. 2. ${ }^{\circ}$ verbis: "Aplica-se esta Lei, sem prejuízo de convenções e tratados de que seja signatário o Brasil, às práticas cometidas no todo ou em parte no território nacional ou que nele produzam ou possam produzir efeitos. ${ }^{39}$

Neste sentido, é necessário retomar os esforços para que as preocupações de países ainda não plenamente desenvolvidos, como é o caso do Brasil, sejam adequadamente refletidas em regras internacionais adaptáveis às diferentes circunstâncias e estágios econômicos, tecnológicos, sociais, ambientais, entre outros. Tanto mais que, no caso brasileiro, os PPBs representam políticas industriais clivadas segundo mandamentos constitucionais e conformes ao desenho institucional conferido à tutela da indústria nacional.

\section{Conclusão}

A ZFM continua sendo objeto de discussões não apenas dentro do Brasil, mas, especialmente, no plano do comércio internacional, a partir do momento em que a concorrência se acirra. A ZFM não é uma zona franca nos termos usuais do comércio, mas trata-se de região com políticas industriais específicas. Para compreender parte do problema suscitado pela criação de PPBs trouxemos os princípios da OMC para que a questão pudesse ter um olhar abrangente sem nos afastarmos de todos os princípios que balizam o comércio internacional.

Partiu-se de uma premissa inicial de que o PPB deve ser visto como um política necessária ao desenvolvimento regional. Nesse sentido, com base em nosso objetivo central, a reflexão situa-se em duas bases: i. nos princípios que regem a $\mathrm{OMC}$ e, ii. nos pressupostos constitucionais e agenda brasileira de desenvolvimento.

Ao se avaliar a compatibilidade das políticas industriais da ZFM, especificamente PPBs, pudemos concluir, em primeiro lugar, que o contexto de globalização comercial não é e não deve ser excludente à elaboração e execução de políticas internas de desenvolvimento

\footnotetext{
${ }^{39}$ BRASIL. Superior Tribunal de Justiça. Mandado de Segurança n. ${ }^{\circ}$ 11.862-DF. Relatora: Ministra Eliana Calmon. Julgado em 22 de abril de 2009, p. 18-19.
} 
relacionadas ao apoio à indústria doméstica, especificamente considerando realidades regionais e a necessidade de tratamento diferenciado.

Contudo, o presente estudo não ignora que a questão, para ser bem aceita dentro do comércio global, precisará de análise mais atenta e contextualizada com a consequente manifestação da própria OMC. Desse modo, as demandas recentes procuraram endereçar ao Sistema de Solução de Controvérsias da OMC uma análise pormenorizada da politica industrial desenvolvida na ZFM.

Respostas ainda não foram dadas pelo próprio OSC, mas considerando que o tema deve ser analisado em breve, espera-se uma avaliação abrangente diante da realidade regional da ZFM que ainda motiva os estímulos regionais, i.e., aceitando a assimetria entre os Membros da OMC e compreendendo que determinados atores globais ainda necessitam de esforços maiores para a ampliação do espaço de implantação de políticas de desenvolvimento no contexto multilateral. 


\section{REFERÊNCIAS BIBLIOGRÁFICAS}

AMARAL, Antonio Carlos Rodrigues do (coord). Direito do comércio internacional: aspectos fundamentais. São Paulo: Aduaneiras, 2004.

BARRAL, Welber; REIS, Geraldo Antônio. Globalização e o novo marco regulatório do comércio internacional: a inserção brasileira. Ensaios FEE, v.20, n.1, p. 179-208, 1999.

BRASIL. CNI. Políticas Industriais Brasileiras em Cheque: Questionamento da União Europeia contra o Brasil na OMC. Observatório de Defesa Comercial, vol. 3, n. ${ }^{\circ}$, jan./abr. 2014.

BRASIL. Superior Tribunal de Justiça. Mandado de Segurança n. ${ }^{\circ}$ 11.862-DF. Relatora: Ministra Eliana Calmon. Julgado em 22 de abril de 2009.

CELLI Júnior, Umberto. Os acordos de serviços (GATS) e de investimento (TRIMS) na OMC: espaço para políticas de desenvolvimento. Cadernos PROLAM/USP, vol. 1, 2007.

CNI. Políticas Industriais Brasileiras em Cheque: Questionamento da União Europeia contra o Brasil na OMC. Observatório de Defesa Comercial, vol. 3, n. ${ }^{\circ}$ 1, jan./abr. 2014, p. 1-8.

CRETELlA NETO, José. Direito processual na Organização Mundial do Comércio, OMC: casuística de interesse para o Brasil. Rio de Janeiro: Forense, 2003.

DOMINGUES, Juliana Oliveira; OLIVEIRA, Cristina B. G. de. Direito Econômico Internacional. Curitiba: Intersaberes, 2017.

HOEKMAN, Bernard M.; KOSTECHI, Michel M. The political economy of the world trading system. 2. Ed. New York: Oxford University Press, 2002.

JACKSON, John H. The world trading system. Law and Policy of International Economic Relations. 2. Ed. Massachusetts Institute of Technology, 1997.

LAFER, Celso. A OMC e a regulamentação do comércio internacional: uma visão brasileira. Porto Alegre: Livraria do Advogado, 1998.

OLIVEIRA, Ivan Tiago Machado; Thorstensen, Vera. Multilateralismo comercial em xeque: que regulação do comércio internacional no século XXI. In: IPEA. Diretoria de Estudos e Relações Econômicas e Políticas Internacionais. Boletim de economia política e política internacional/ Instituto de Pesquisa Econômica Aplicada. n. 1. Brasília, 2010.

RODRICK, Nelson. Trading in Illusions. Foreign Policy, 18 de novembro de 2009. Disponível em: <http://foreignpolicy.com/2009/11/18/trading-in-illusions/> Acesso em: maio 2017.

SALDANHA, Eduardo. Desenvolvimento e tratamento especial e diferenciado na OMC: uma abordagem sob a perspectiva da doutrina do stare decisis - Parte I. Revista de Direito Econômico e Socioambiental. v.3. n.1. pp. 11-42. 2012. 
SCHWARTZ, Gilson. Conferência de Bretton Woods (1944). In: MAGNOLI, Demétrio (org.). História da Paz. São Paulo: Contexto, 2008.

SEN, Amartya. Desenvolvimento como liberdade. São Paulo: Companhia das Letras, 2000.

THORSTENSEN, Vera. OMC - As Regras do Comércio Internacional e a Rodada do Milênio. São Paulo: Aduaneiras, 1999.

THORSTENSEN, Vera; RAMOS, Daniel; MULLER, Carolina. O Princípio da Nação Mais Favorecida e os desalinhamentos cambiais. Instituto de Pesquisa Econômica Aplicada. Brasília, 2011.

TREBILCOCK, Michael; HOWSE, Robert; ELIASON, Antonia. The Regulation of International Trade. 4. Ed. Routledge, 2012.

VALERIO, Marco Aurélio Gumieri. Organização Mundial do Comércio - Novo ator na esfera internacional. Revista de informação legislativa, v. 46, n. 184, p. 121-130, out./dez. 2009.

UNCTAD. CONFERÊNCIA DAS NAÇÕES UNIDAS PARA COMÉRCIO E DESENVOLVIMENTO. Solução de Controvérsias. OMC. Nova York e Genebra, 2003.

WTO. The GATT years: from Havana to Marrakesh. 2016. Disponível em: < https://www.wto.org/english/thewto_e/whatis_e/tif_e/fact4_e.htm>. Acesso em: 14 mai. 2016. 